\title{
Optical Properties of Blown Films of PA6/MMT Nanocomposites
}

\author{
Juliano Marini ${ }^{a}$, Rosario Elida Suman Bretas ${ }^{a}$ \\ ${ }^{a}$ Department of Materials Engineering, Universidade Federal de São Carlos, Rodovia Washington Luis, \\ km 235, 13565-905, São Carlos, Brazil
}

Received: March 13, 2017; Revised: August 16, 2017; Accepted: September 19, 2017

\begin{abstract}
In this work blown films of polyamide 6 (PA6) nanocomposites were produced at different processing conditions, with the addition of montmorillonite (MMT), pure and surface modified by an organic salt. The films' optical properties were evaluated according to ASTM D-1003 and the results correlated with the degree of crystallinity, nanoparticle's dispersion state and processing conditions. It was observed that the thinner the film, the lower the haze and higher the clarity, due to the presence of less internal scattering structures in the direction of the incident light. The PA6 films with the unmodified MMT had the lowest clarity values, due to nanoparticles' agglomeration. The organic modification of the montmorillonite led to its exfoliating through the PA6 matrix, resulting in an optimization of the films' optical properties (decreased haze and increased clarity) when compared to the pure PA6 films.
\end{abstract}

Keywords: optical properties, nanocomposites, blown films

\section{Introduction}

In recent years, there has been a major growth in the global packaging market, driven by a number of factors such as increasing urbanization, health sector expansion and the rapid development of emerging economies ${ }^{1}$. Only in Brazil, the production value of this sector was estimated at US\$14.4 billion in 2015, corresponding to approximately $1 \%$ of the gross domestic product (GDP) ${ }^{2}$. One of the major trends in the sector is the gradual replacement of metals and glass by plastic packaging, due to factors such as low density, flexibility, processability and transparency. However, there are some limitations, mainly related to the permeation behavior and thermal resistance of these materials ${ }^{3}$.

Flexible polymer packages can be obtained from two main processes: flat and blown film extrusion, producing mono and multilayer films. The properties of the polymer film are dependent on the processing conditions, which also influence the final morphology. Polymers are conventionally processed under high deformation rates in shear and/or elongational flows, inducing orientation of the polymer chains and, depending on the relaxation time of the polymer and the applied cooling rate, such orientation can be maintained in the final product, leading to highly anisotropic behaviors. The blown film extrusion process is one of the conformation methods where this orientation is more pronounced. The variation of the take-up (TUR) and blow-up (BUR) ratios, coupled with a high cooling rate leads to obtaining biaxial oriented films ${ }^{4-7}$.

Therefore, the development of more efficient packaging depends on the understanding of the processes and materials used. In the last decades, the use of nanoparticles (NPs)

*e-mail: juliano.marini@ufscar.br. as reinforcing agents in polymeric matrices has been the focus of many research groups ${ }^{8-13}$. The incorporation of small contents (usually less than 5\%) of these fillers can lead to improvements in the mechanical, thermal and barrier properties in magnitude comparable to the use of high levels of conventional micro-sized fillers. This optimized state is reached when the NPs are well dispersed and distributed through the matrix and when there are good polymer-NP interactions (forming an efficient interface); in this case, NPs with high aspect ratio and high surface area can lead to even more significant improvements in final properties ${ }^{14}$.

In the packaging area, optical properties, such as haze, gloss, clarity or transparency and transmittance, are critical factors in determining the final use of the product. The scattering of visible light can occur due to the presence of superficial or internal crystalline structures, and its extent depends on the size of such structures: if they are in a similar range to that of the light wavelength (between 400 and $700 \mathrm{~nm}$ ), the phenomena of diffuse reflection, refraction and scattering occur considerably, resulting in increased turbidity $7,15,16$.

In this work blown films of polyamide 6 (PA6) nanocomposites were produced at different processing conditions, with the addition of montmorillonite, pure and surface modified by an organic salt. The films' optical properties were evaluated and the results correlated with the degree of crystallinity, NPs dispersion state and processing conditions.

\section{Experimental}

\subsection{Materials}

A high viscosity grade of polyamide 6 (Mazmid B400, from Mazzaferro Industria e Comercio de Polimeros e Fibras 
Ltda) with residual monomer content of $0.3 \mathrm{wt} \%$, density of $1.14 \mathrm{~g} / \mathrm{cm}^{3}$, and melt flow index of $2.5 \mathrm{~g} / 10 \mathrm{~min}\left(235^{\circ} \mathrm{C} / 2.16 \mathrm{Kg}\right)$ was chosen as matrix of the nanocomposites. Two different types of lamellar montmorillonites were used as reinforcing nanoparticles: Cloisite ${ }^{\circledR} \mathrm{Na}^{+}$, from Southern Clay Products, Inc., a sodium aluminosilicate nanoparticle without organic modification (identified here as MMT) and Closite ${ }^{\circledR}$ 30B, also from Southern Clay Products, Inc., a MMT organically modified with a quaternary ammonium salt (oMMT).

\subsection{Compounding}

The nanocomposites with $5 \mathrm{wt} \%$ of NPs were produced by melt mixing using co-rotational twin-screw extrusion process. A two steps methodology was chosen: production of 70/30 wt/wt PA6/NP masterbatches, with further dilution in the PA6 matrix. The masterbatches were obtained in a MP19 extruder, from B\&P Process Equipment Systems, at $120 \mathrm{rpm}$, temperature profile in the $245-260^{\circ} \mathrm{C}$ range, and residence time of $75 \mathrm{~s}$. The screw profile used was described by Martins et al. ${ }^{17}$. The dilution process was done in a ZSK 30 extruder, from Werner \& Pfleiderer, at $120 \mathrm{rpm}$, temperature profile between 245 and $255^{\circ} \mathrm{C}$, and residence time of approximately $100 \mathrm{~s}$. The screw profile used was described by Beatrice et al ${ }^{9}$. For comparison purposes, the neat PA6 was processed at the same conditions that the nanocomposites. Before all processing steps, the PA6 was dried in an air circulation oven at $110^{\circ} \mathrm{C}$ during $16 \mathrm{~h}$ and the NPs were vacuum dried at $80^{\circ} \mathrm{C}$ during $16 \mathrm{~h}$.

\subsection{Nanocomposites characterization}

The extent of MMT intercalation and/or exfoliation in the extruded PA6/NP nanocomposites were analyzed by wide angle X-ray diffraction (WAXD) using a Rigaku diffractometer, model Ultima IV, with $\mathrm{CuK}_{\alpha}$ radiation $(\lambda$ $=1.542 \AA$ ), operated at $40 \mathrm{kV}$ and $40 \mathrm{~mA}$. Samples were scanned between 1.5 and $12^{\circ}$, at a rate of $1 \% \mathrm{~min}$.

Rheological measurements were used to evaluate interactions and the dispersion state of NPs through the PA6 matrix. $G^{\prime}(\omega)$ and $G^{\prime \prime}(\omega)$ were measured as function of the frequency $(\omega)$ in a controlled strain ARES rheometer, from Rheometric Scientific, using a $25 \mathrm{~mm}$ parallel-plate fixture, gap of $1 \mathrm{~mm}$, at $250^{\circ} \mathrm{C}$, under nitrogen atmosphere. A strain sweep test was done previously, for all samples, to select the strain amplitude within the linear viscoelastic range of each material. Measurements of creep and constrained recoil (recovery) after steady state shear flow were done in a controlled stress ARG2 rheometer, from TA Instruments, using a $25 \mathrm{~mm}$ parallel-plate fixture, gap of $1 \mathrm{~mm}$, at $250^{\circ} \mathrm{C}$, under nitrogen atmosphere. During the creep experiments, a constant shear stress of 1,000 $\mathrm{Pa}$ was applied during 2 min. To measure the constrained recoil, the shear stress was suddenly removed. In both experiments, the strain was monitored as a function of time. The recovery strain after 2 min was calculated from:

$$
\gamma_{r}=\left[\frac{\gamma_{\text {total }}-\gamma_{\text {final }}}{\gamma_{\text {total }}}\right] \times 100
$$

where $\gamma_{\text {total }}$ is the strain after 2 min of stress application and $\gamma_{\text {final }}$ is the strain after 2 min of stress removal. Before all rheological testing, the samples were vacuum dried at $110^{\circ} \mathrm{C}$ during $16 \mathrm{~h}$.

\subsection{Films blowing}

Blown films of PA6 and PA6/NP nanocomposites were produced using a $25 \times 30 \mathrm{D}$ lab scale single screw extruder from Indústria de Máquinas Miotto Ltda. The spiral extrusion head presented an annular die with external and internal diameters of 80.0 and $78.4 \mathrm{~mm}$, respectively. The screw rotation was fixed at $60 \mathrm{rpm}$, the temperature profile between 245 and $255^{\circ} \mathrm{C}$, with a residence time of $180 \mathrm{~s}$. Four different processing conditions were used and they are described in Table 1. The cooling of the films was performed at room temperature, with the aid of a compressed air system (with air flow in the internal and external surfaces of the bubble). Due to the size and design of the equipment used and the characteristics of the materials, it was not possible to observe the height of the freeze line during the production of the blown films.

Table 1. Processing conditions of the blown films. $\mathrm{N}=$ screw rotation, $\mathrm{TUR}=$ take-up ratio, $\mathrm{BUR}=$ blow-up ratio and $\mathrm{H}=$ films' thickness.

\begin{tabular}{ccccc}
\hline Condition & N (rpm) & TUR & BUR & H $(\mu \mathrm{m})$ \\
\hline C1 & 60 & 10 & 1 & $90-100$ \\
C2 & 60 & 10 & 2 & $45-55$ \\
C3 & 60 & 20 & 1 & $45-55$ \\
C4 & 60 & 20 & 2 & $25-35$ \\
\hline
\end{tabular}

\subsection{Films characterization}

The influence of the NPs and processing conditions on the crystallinity of the blown films were evaluated by differential scanning calorimetry (DSC) using a QS100 equipment (TA Instruments) at a heating rate of $10^{\circ} \mathrm{C} / \mathrm{min}$ between 25 and $250^{\circ} \mathrm{C}$, under $\mathrm{N}_{2}$ flux. The degree of crystallinity $\left(\mathrm{X}_{\mathrm{c}}\right)$ was calculated from:

$$
X_{c}=\frac{\Delta H_{f}-\Delta H_{c c}}{(1-\phi) \cdot \Delta H_{f}^{0}} \times 100 \%
$$

where $\Delta \mathrm{H}_{\mathrm{f}}$ is the sample enthalpy of fusion, $\Delta \mathrm{H}_{\mathrm{cc}}$ is the enthalpy of cold crystallization, $\Delta \mathrm{H}^{0}{ }_{f}$ is the enthalpy of fusion for a $100 \%$ crystalline polymer sample (for PA6, $\Delta \mathrm{H}_{f}^{0}=240$ $\mathrm{J} / \mathrm{g}^{18}$ ) and $\phi$ is the mass fraction of NP.

Modifications on the extent of MMT intercalation and/ or exfoliation after the films' blowing process were analyzed by WAXD using the same equipment and test conditions described before (section 2.3).

The dispersion and distribution of the oMMT through the PA6 matrix were analyzed using transmission electron 
microscopy (TEM), in an equipment from Philips, model CM120, operated at $120 \mathrm{kV}$. Samples with $40 \mathrm{~nm}$ of thickness were prepared by cryo-ultramicrotomy at $-50^{\circ} \mathrm{C}$, using a microtome from Leica, model Reichert-Jung Ultracut E. The blown films were previously embedded in epoxy resin (cured at $70^{\circ} \mathrm{C}$ during $12 \mathrm{~h}$ ). From the TEM micrographics, the average aspect ratio of NPs was quantified.

Haze, transmittance and clarity of the films were measured in a Haze-Gard Plus equipment from BYK-Gardner according to ASTM D-1003-13.

\section{Results and Discussion}

\subsection{Nanocomposites characterization}

The extent of intercalation and/or exfoliation of the NPs lamellae was evaluated by WAXD (Figure 1). Table 2 shows the basal spacing $\left(\mathrm{d}_{001}\right)$ of the NPs in the nanocomposites, calculated from the Bragg's law. The WAXD spectrum of the PA6/MMT nanocomposite showed two peaks: the first one, at $2 \theta \sim 4.2^{\circ}$ is related to the (001) plane of MMT and the second one, which is multiple of the first, is related to parallel planes of the $\{001\}$ family. It can be observed a slight increase in the basal spacing when compared to the pure MMT, indicating a limited intercalation of the PA6 chains into the MMT galleries. On the other hand, for the PA6/oMMT nanocomposite, the diffraction peak related to the NP was not observed, showing that an extensive exfoliation process occurred during the mixture. These results are standard to nanocomposites based on PA6 matrix 9, 14, 18, 19; the exfoliation occurs when high levels of stress (shear and elongational) are applied during the processing of nanocomposites with increased affinity between the matrix and the reinforcing filler (due to the organic modification of the MMT).

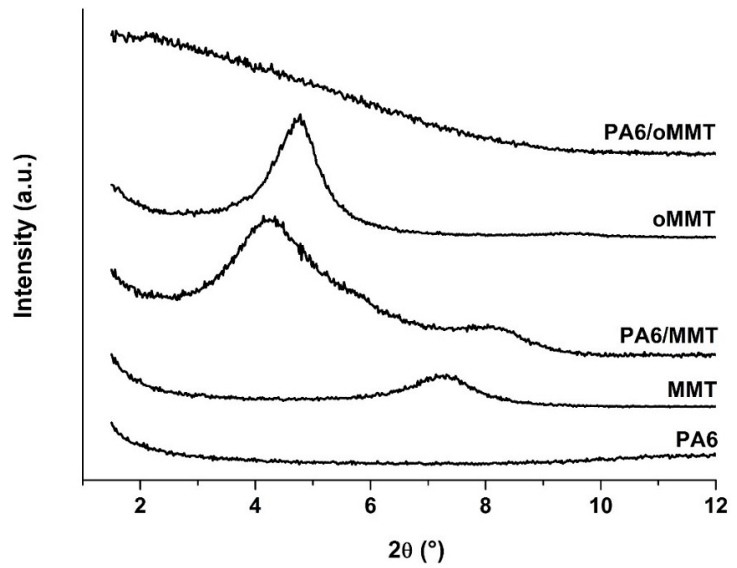

Figure 1. WAXD diffractograms of the PA6, nanoparticles and nanocomposites obtained by twin-screw extrusion.

The NP content used ( $5 \mathrm{wt} \%$ ) was above the theoretical percolation threshold (estimated as $2 \mathrm{wt} \%{ }^{14}$ ). Many authors ${ }^{9,14,20}$ have used oscillatory shear rheological tests as a
Table 2. Parameters obtained from WAXD $(\theta=$ diffraction angle, $\mathrm{d}_{001}=$ MMT's basal spacing) and rheological $\left(\alpha=\right.$ slope of $\mathrm{G}^{\prime}(\omega)$ or $\mathrm{G}^{\prime \prime}(\omega)$ curves at terminal zone, $\gamma_{\mathrm{r}}=$ recovery strain) measurements for the extruded samples.

\begin{tabular}{cccccc}
\hline Sample & $2 \theta\left({ }^{\circ}\right)$ & $\mathrm{d}_{001}(\mathrm{~nm})$ & $\alpha\left(\mathrm{G}^{\prime}\right)$ & $\alpha\left(\mathrm{G}^{\prime \prime}\right)$ & $\gamma_{\mathrm{r}}(\%)$ \\
\hline PA6 & --- & --- & 1.42 & 0.61 & 0.07 \\
MMT & 7.3 & 1.2 & --- & --- & --- \\
PA6/MMT & 4.2 & 2.1 & 1.05 & 0.41 & 0.12 \\
oMMT & 4.8 & 1.8 & --- & --- & --- \\
PA6/oMMT & $<1.5$ & $>5.9$ & 0.38 & 0.27 & 34.60 \\
\hline
\end{tabular}

tool to evaluate the state of dispersion of the NPs since these particules alter the viscoelastic properties of the polymeric matrix. The curves of storage $\left(\mathrm{G}^{\prime}\right)$ and loss $\left(\mathrm{G}^{\prime \prime}\right)$ moduli as function of the frequency $(\omega)$ are shown in Figure 2.a and the values of the slopes $(\alpha)$ of these curves in the terminal zone $(\omega \rightarrow 0)$ were calculated and are presented in Table 2 . The neat PA6 had a pronounced elastic behavior $\left(\mathrm{G}^{\prime}>\mathrm{G}^{\prime \prime}\right.$ in the terminal zone). For the chosen conformational process (blown film extrusion) this behavior is essential, since the material needs high melt strength. For this particular PA6 grade, the presence of a $0.3 \mathrm{wt} \%$ content of residual monomer allows the material to maintain its melt strength in a proper value even after the different processing steps ${ }^{9}$. The addition of NPs increased the elastic and viscous moduli of the nanocomposites. The best result was observed in the PA6/ oMMT nanocomposite due to the exfoliation process and higher affinity with the matrix; the better dispersed oMMT particles acted as entanglements points, anchoring the PA6 chains during the oscillatory tests and the nanocomposite showed a pseudo-solid behavior, indicating the formation of a percolated network. This behavior is also observed in the creep/recovery tests (Figure 2.b and Table 2). The strain during creep test $(0.52)$ and recovery strain $\left(\gamma_{\mathrm{r}}\right)$ after $2 \mathrm{~min}$ $(34.6 \%)$ for the PA6/oMMT nanocomposite indicated a highly elastic behavior when compared to the PA6 (66.36 and $0.07 \%$, respectively) and PA6/MMT nanocomposite (167.37 and $0.12 \%$, respectively).

\subsection{Films characterization}

Figure 3 shows the DSC curves of the PA6 and PA6/NP blown films; the values of $\mathrm{X}_{\mathrm{c}}$ are shown in Table 3. For all films, a transition in the region between 80 and $130^{\circ} \mathrm{C}$ was observed, possibly related to the presence and relaxation of a rigid amorphous phase formed during the processing. The existence of a rigid amorphous phase (RAP) in different semicrystalline polymers (including PA6) has been extensively studied, being characterized as an intermediate component between the amorphous and crystalline phases ${ }^{21,22}$. The wide range of temperatures where this phenomenon occurred should be related to the different processing conditions used, which impact the films' thickness, crystallization process and lamellae orientation. In addition, it is possible to observe 



Figure 2. Rheological characterization of the extruded samples, at $250^{\circ} \mathrm{C}$ : (a) $\mathrm{G}^{\prime}(\omega)$ and $\mathrm{G}^{\prime \prime}(\omega)$; (b) creep $(\tau=1,000 \mathrm{~Pa}, \mathrm{t}=120 \mathrm{~s})$ and constrained recoil $(\tau=0 \mathrm{~Pa}, \mathrm{t}=120 \mathrm{~s})$.

an exothermic crystallization peak at approximately $195^{\circ} \mathrm{C}$, related to the transformation of part of the $\gamma$-phase of PA6 into $\alpha$-phase during heating. With the exception of the PA6 film obtained in the $\mathrm{C} 1$ processing condition, two melting peaks were observed for all other films $\left(\right.$ at $210^{\circ} \mathrm{C}$ and $220^{\circ} \mathrm{C}$, approximately). Some authors have correlated the presence of the peak at lower temperature to the crystalline fusion of the PA6 $\gamma$-phase since this type of crystal presents a lower degree of packing, when compared to the $\alpha$-phase one ${ }^{23,24}$. However, it is incorrect to state and evaluate these peaks as distinct crystalline phases using only the curves obtained by DSC, since they could be reflecting the presence of lamellae with different and large distribution sizes, for example. The interpretation of the DSC curves in this case is not an easy task since multiple transitions could be observed during heating (relaxation of RAF, cold crystallization, and multiple melting peaks) and some of them were overlapped. Thus, greater deviations in the values are expected, making quantitative analysis difficult. As a general trend, it can be stated that more severe processing conditions (higher take-up and blowup ratios) lead to higher degree of crystallinity in the PA6 films. In addition, the presence of NPs also influences the crystallization process; for the same processing condition,
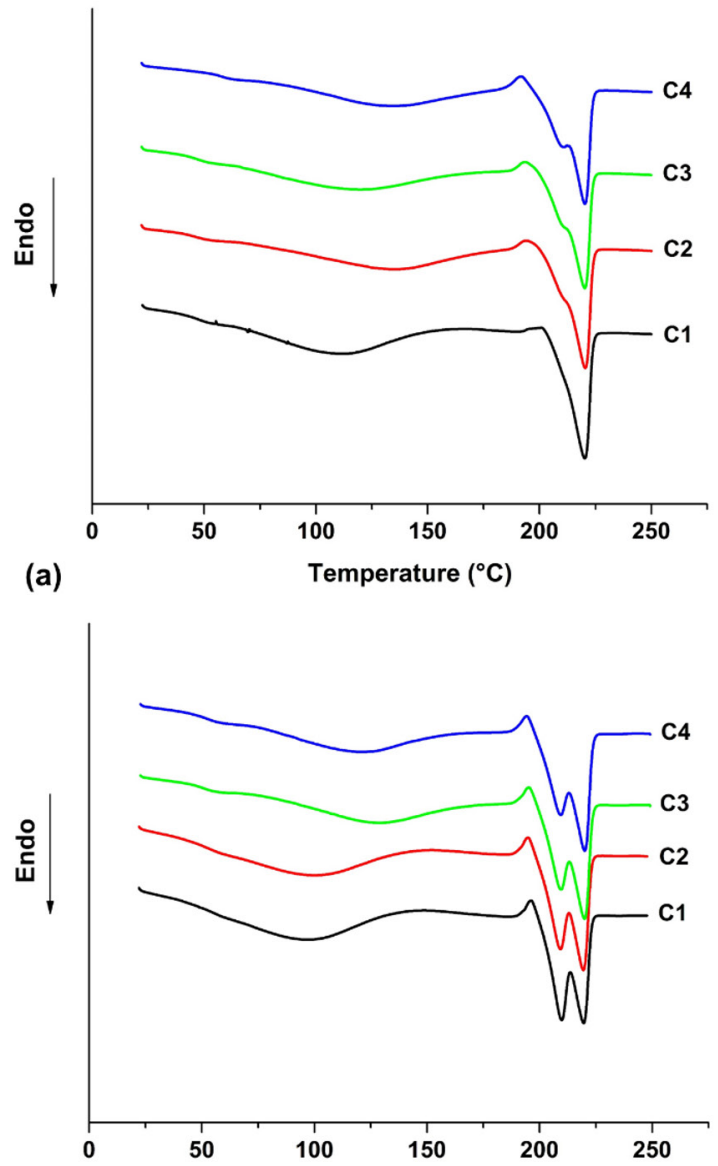

(b) Temperature $\left({ }^{\circ} \mathrm{C}\right)$

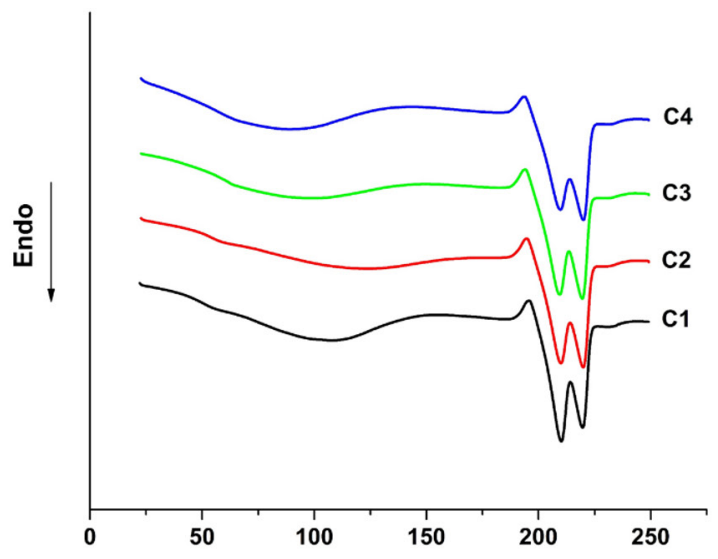

(c)

Temperature $\left({ }^{\circ} \mathrm{C}\right)$

Figure 3. DSC curves of the blown films obtained in different processing conditions $(\mathrm{C} 1, \mathrm{C} 2, \mathrm{C} 3$ and $\mathrm{C} 4)$ : (a) PA6; (b) PA6/ MMT; (c) PA6/oMMT.

the $X_{c}$ of the PA6/MMT nanocomposite films tends to be slightly higher than that of the pure PA6 film. On the other hand, the PA6/oMMT nanocomposite films did not show significant variation of $X_{c}$ at the different processing conditions and had values of $X_{c}$ similar to or lower than the pure PA6 films. Such behavior may be explained by 
Table 3. Parameters obtained from DSC $\left(X_{c}=\right.$ degree of crystallinity $)$, WAXD ( $\theta=$ diffraction angle, $d_{001}=$ MMT's basal spacing $)$ and TEM $(\mathrm{L}=$ length, $\mathrm{D}=$ thickness and $\mathrm{L} / \mathrm{D}=$ average aspect ratio of the oMMT particles in the PA6 matrix) measurements for the blown film samples.

\begin{tabular}{|c|c|c|c|c|c|c|}
\hline Sample & $X_{c}(\%)$ & $2 \theta\left({ }^{\circ}\right)$ & $\mathrm{d}_{001}(\mathrm{~nm})$ & $\mathrm{L}(\mathrm{nm})$ & $\mathrm{D}(\mathrm{nm})$ & $\mathrm{L} / \mathrm{D}$ \\
\hline PA6 C1 & 23 & --- & --- & --- & --- & --- \\
\hline PA6 C2 & 24 & --- & --- & --- & --- & --- \\
\hline PA6 C3 & 25 & --- & --- & --- & --- & --- \\
\hline PA6 C4 & 26 & --- & --- & --- & --- & --- \\
\hline PA6/MMT C1 & 25 & 4.6 & 1.9 & --- & --- & --- \\
\hline PA6/MMT C2 & 26 & 4.3 & 2.0 & --- & --- & --- \\
\hline PA6/MMT C3 & 25 & 4.4 & 2.0 & --- & --- & --- \\
\hline PA6/MMT C4 & 26 & 4.3 & 2.0 & --- & --- & --- \\
\hline PA6/oMMT C1 & 24 & $<1.5$ & $>5.9$ & $110.1 \pm 27.5$ & $1.9 \pm 0.7$ & $63.7 \pm 27.0$ \\
\hline PA6/oMMT C2 & 23 & $<1.5$ & $>5.9$ & $121.3 \pm 32.8$ & $1.9 \pm 0.6$ & $73.4 \pm 36.5$ \\
\hline PA6/oMMT C3 & 24 & $<1.5$ & $>5.9$ & $110.6 \pm 41.6$ & $1.9 \pm 0.6$ & $61.9 \pm 28.7$ \\
\hline PA6/oMMT C4 & 23 & $<1.5$ & $>5.9$ & $94.5 \pm 28.3$ & $1.8 \pm 0.6$ & $60.6 \pm 28.3$ \\
\hline
\end{tabular}

the inability of the polymer chains to be fully incorporated by the growing crystal lamellae during the crystallization process: the presence of well dispersed oMMT lamellae in the PA6 matrix prevents the formation of large crystalline domains due to spatial restrictions imposed on the polymer chains by the high aspect ratio silicate lamellae, generating smaller crystals with more defects ${ }^{18}$.

The WAXD diffractograms of the blown films are shown in Figure 4. Comparing the values of $d_{001}$ (Table 3) with those obtained for the nanocomposites produced by twin-screw extrusion, it can be noted that there were no significant variations in the basal distance of the NPs, regardless the processing condition. It indicates that applying more shear and elongational stresses have a limited influence on the exfoliation process of the lamellar silicates in polymeric matrices, being only effective for the initial breaking of the montmorillonite tactoids. The exfoliation is only attained when there is a good affinity between the matrix and the oMMT. It should also be noted that the addition of NPs induces a higher crystallization of the PA6 $\gamma$-phase, as can be seen by the characteristic diffraction peak at $2 \theta=$ $10.5^{\circ}$. The $\gamma$-phase is less stable than the $\alpha$-phase, with its formation being favored in conditions of rapid cooling, low temperatures and presence of fillers ${ }^{18}$.

TEM micrographs of the PA6/oMMT films are shown in Figure 5. In general, the nanocomposites presented a good dispersion and distribution of the oMMT in the polymeric matrix. An extensive exfoliation of the oMMT can be observed, corroborating with the WAXD data. The average values of length, thickness and aspect ratio (Table 3 ) of the oMMT particles are approximately $110 \mathrm{~nm}, 1.9 \mathrm{~nm}$ and 65 , respectively. It is very important to measure these geometric/shape characteristics since they will affect the optical behavior of the films.

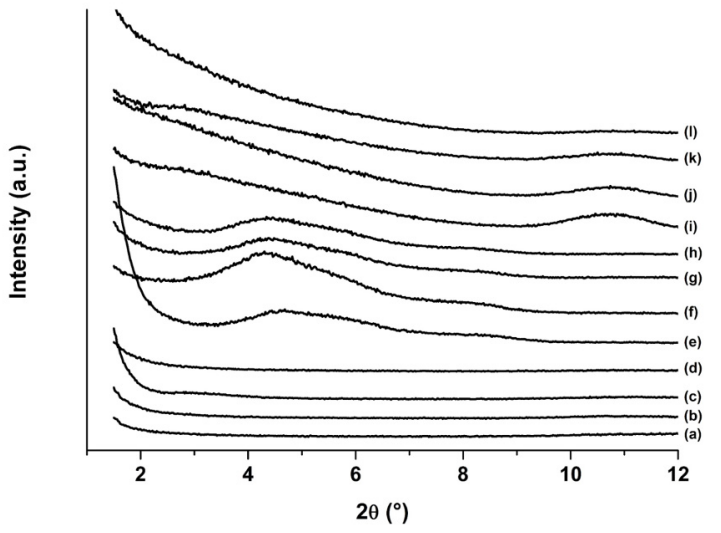

Figure 4. WAXD diffractograms of the blown films: (a) PA6 $\mathrm{C} 1$; (b) PA6 C2; (c) PA6 C3; (d) PA6 C4; (e) PA6/MMT C1; (f) PA6/ MMT C2; (g) PA6/MMT C3; (h) PA6/MMT C4; (i) PA6/oMMT C1; (j) PA6/oMMT C2; (k) PA6/oMMT C3; (l) PA6/oMMT C4.

Table 4 presents the optical properties of the blown films (total haze, transmittance and clarity), measured according to ASTM D-1003. Haze can be defined as the scattering of light in a specimen and is responsible for the reduction in contrast of objects seen through it, corresponding to the percentage of transmitted light that is scattered in a direction that deviates more than an angle of $2.5^{\circ}$ compared to incident beam ${ }^{25}$. Haze can be divided in internal, occurring by light scattering in regions of different refractive indices, generated by a local anisotropy due to different morphological arrangements and degrees of crystallinity, and external, due to superficial irregularities (roughness). In the methodology used for the measurement, the total haze values of the blown films were obtained. Transmittance is the fraction of incident light passing through a specimen; is a factor related to the absorptance, or absorption power, which is the fraction of radiation absorbed by a sample. Clarity is defined as the 


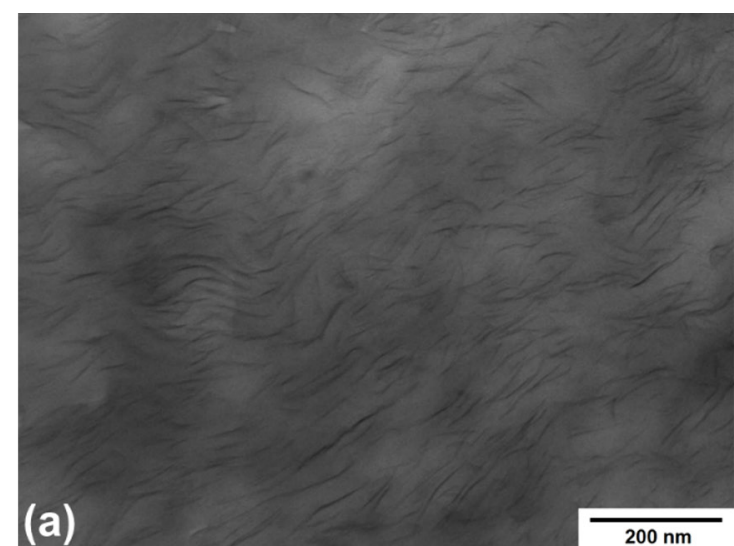

$200 \mathrm{~nm}$

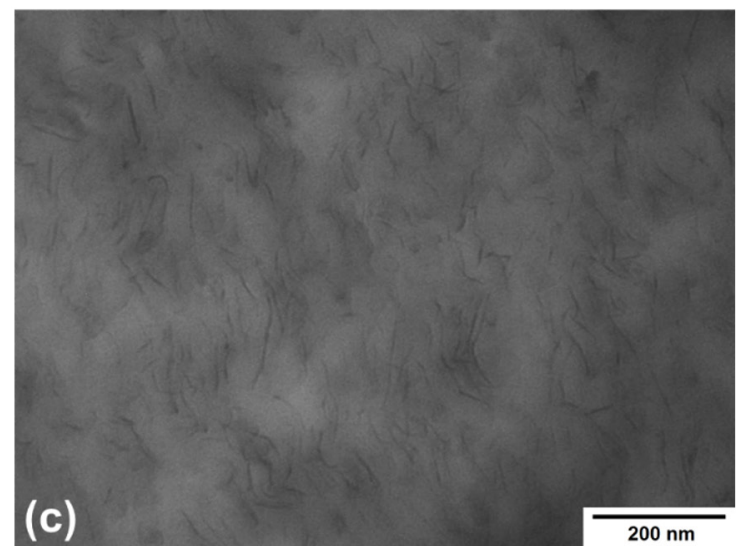

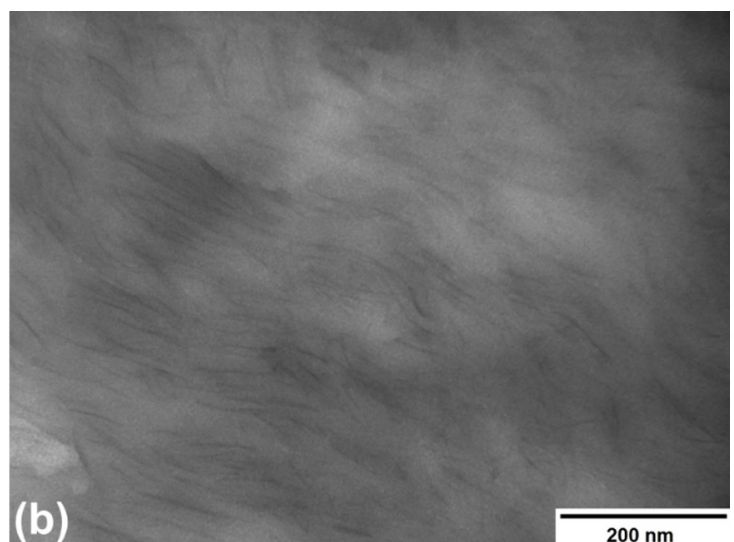

$200 \mathrm{~nm}$

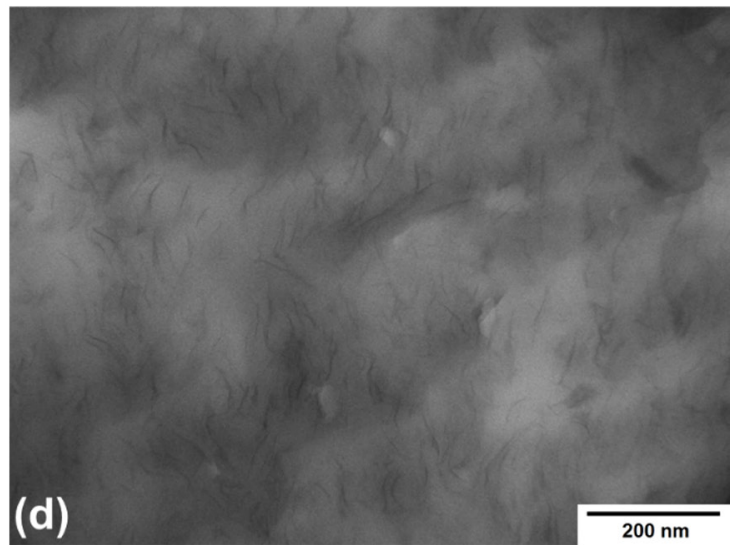

Figure 5. TEM micrographs of the PA6/oMMT blown films obtained in different processing conditions: (a) C1; (b) C2; (c) C3; (d) C4.

Table 4. Optical properties of the blown films.

\begin{tabular}{cccc}
\hline Sample & Haze (\%) & Transmittance (\%) & Clarity (\%) \\
\hline PA6 C1 & $42.0 \pm 4.6$ & $88.1 \pm 0.9$ & $91.3 \pm 2.1$ \\
PA6 C2 & $22.0 \pm 1.2$ & $90.7 \pm 0.5$ & $95.5 \pm 0.9$ \\
PA6 C3 & $15.6 \pm 1.9$ & $91.2 \pm 0.7$ & $92.0 \pm 3.2$ \\
PA6 C4 & $9.5 \pm 0.8$ & $91.5 \pm 0.3$ & $96.3 \pm 0.8$ \\
PA6/MMT C1 & $32.3 \pm 8.9$ & $84.6 \pm 4.5$ & $47.9 \pm 0.9$ \\
PA6/MMT C2 & $26.3 \pm 1.6$ & $87.1 \pm 0.3$ & $47.3 \pm 0.6$ \\
PA6/MMT C3 & $34.3 \pm 3.7$ & $88.2 \pm 0.7$ & $41.8 \pm 2.8$ \\
PA6/MMT C4 & $36.1 \pm 1.1$ & $89.5 \pm 0.3$ & $43.0 \pm 1.7$ \\
PA6/oMMT C1 & $25.9 \pm 2.4$ & $87.0 \pm 0.5$ & $97.0 \pm 0.1$ \\
PA6/oMMT C2 & $12.9 \pm 0.5$ & $89.4 \pm 0.6$ & $98.3 \pm 0.1$ \\
PA6/oMMT C3 & $13.6 \pm 0.8$ & $89.0 \pm 0.6$ & $96.8 \pm 0.4$ \\
PA6/oMMT C4 & $6.7 \pm 0.9$ & $90.6 \pm 0.1$ & $98.6 \pm 0.2$ \\
\hline
\end{tabular}

percentage of transmitted light that is scattered at an angle of less than $2.5^{\circ}$ relative to the direction of incident light; the greater the clarity, the greater the transparency of a film.

Regarding the different processing conditions, it can be verified that the smaller the thickness of the film, the smaller its haze and, consequently, the greater its clarity. Such behavior can be explained by the smaller amount of internal scattering structures in the direction of incident light. In addition, there is a slight decrease in light absorption, with consequent increase in transmittance. As there is no large variation of $\mathrm{X}_{\mathrm{c}}$ between the blown films, the haze variation can be directly correlated with the surface roughness and presence of nanoparticles. The addition of MMT lead to an increase in haze and a decrease in clarity when compared to pure PA6 
films processed at same conditions. In addition, the effect of the film thickness in the haze values was less pronounced for this system, indicating that the surface roughness plays a major role on the optical behavior. The intercalated and poor dispersed MMT particles tends to agglomerate in large domains, with sizes on a scale similar to light wavelength (between 400 and $700 \mathrm{~nm}$ ), increasing the scattering. The behavior observed for the PA6/oMMT blown films must be emphasized: the optical properties were optimized, with a decrease in haze and an increase in clarity, when compared to the values obtained for pure PA6 films. In addition to a slight drop in the degree of crystallinity, the exfoliation of oMMT lamellae through the PA6 matrix decreased the relative size of the crystalline structures, which did not cause light scattering and consequently did not increase turbidity. It is also necessary to consider a possible reduction of surface roughness, previously demonstrated by Beatrice et al. ${ }^{9}$ in a similar PA6/oMMT system.

\section{Conclusions}

Nanocomposites of PA6 with natural (MMT) and organically modified (oMMT) montmorillonites were prepared by twin-screw extrusion using a two steps masterbatch processing methodology, producing intercalated and exfoliated structures, respectively. Blown films were subsequently obtained at different processing conditions (varying BUR, TUR and, consequently, the film's thickness). The optical properties (haze, transmittance and clarity) were measured and the results correlated with the degree of crystallinity, morphology and processing conditions. As expected, the processing conditions remarkably influenced the haze and clarity values. Furthermore, the nanoparticle dispersion played a major role in the optical behavior: intercalated and agglomerated PA6/MMT films presented the lowest transparency while the exfoliated PA6/oMMT films showed a decrease of haze and increase in clarity when compared to the pure PA6 films. Regarding visual appearance and optical properties, PA6/oMMT nanocomposites may be considered excellent candidates for applications in the packaging area.

\section{Acknowledgements}

The authors thank FAPESP (Process 2006/61008-5) and CNPq (Process 141440/2008-2) for the financial aid.

\section{References}

1. Sarantópoulos CIGL, Rego RA, eds. Brasil Pack Trends 2020. Campinas: ITAL; 2012.

2. Salibe I, ed. ABRE Packaging Guide. 2016. São Paulo: ABRE; 2016.

3. Barão MZ. Embalagens para produtos alimentícios. Curitiba: Tecpar; 2011.
4. Manrich S. Processamento de Termoplásticos: Rosca Única, Extrusão e Matrizes, Injeção e Moldes. São Paulo: Artliber Editora; 2005.

5. Tadmor Z, Gogos CG. Principles of Polymer Processing. New York: John Wiley \& Sons; 2006.

6. Sidiropoulos V, Wood PE, Vlachopoulos J. The Aerodynamics of Cooling of Blown Film Bubbles. Journal of Reinforced Plastics and Composites. 1999;18(6):529-538.

7. Bafna A, Beaucage G, Mirabella F, Skillas G, Sukumaran S. Optical Properties and Orientation in Polyethylene Blown Films. Journal of Polymer Science, Part B: Polymer Physics. 2001;39(23):2923-2936.

8. Alexandre M, Dubois P. Polymer-layered silicate nanocomposites: preparation, properties and uses of a new class of materials. Materials Science and Engineering: R: Reports. 2000;28(12):1-63.

9. Beatrice CAG, Branciforti MC, Alves RMV, Bretas RES. Rheological, mechanical, optical and transport properties of blown films of polyamide 6/residual monomer/montmorillonite nanocomposites. Journal of Applied Polymer Science. 2010;116(6):3581-3592.

10. Marini J, Branciforti MC, Lotti C. Effect of matrix viscosity on the extent of exfoliation in EVA/organoclay nanocomposites. Polymers for Advanced Technologies. 2010;21(6):408-417.

11. Marini J, Pollet E, Averous L, Bretas RES. Elaboration and properties of novel biobased nanocomposites with halloysite nanotubes and thermoplastic polyurethane from dimerized fatty acids. Polymer. 2014;55(20):5226-5234.

12. Olivato JB, Marini J, Yamashita F, Pollet E, Grossmann MVE, Avérous L. Sepiolite as a promising nanoclay for nanobiocomposites based on starch and biodegradable polyester. Materials Science and Engineering: C. 2017;70(Pt 1):296-302.

13. Poisson C, Guerengomba J, Lacrampe MF, Krawczak P, Gupta B, Miri V, et al. Mechanical, Optical and Barrier Properties of PA6/Nanoclay-Based Single- and Multilayer Blown Films. Polymers \& Polymer Composites. 2008;16(6):349-358.

14. Marini J, Bretas RES. Influence of shape and surface modification of nanoparticle on the rheological and dynamic-mechanical properties of polyamide 6 nanocomposites. Polymer Engineering \& Science. 2013;53(7):1512-1528.

15. Callister WD. Ciência e Engenharia de Materiais: Uma Introdução. Rio de Janeiro: LTC; 2002.

16. Soulestin J, Rashmi BJ, Bourbigot S, Lacrampe MF, Krawczak P. Mechanical and Optical Properties of Polyamide 6/Clay Nanocomposites Cast Films: Influence of the Degree of Exfoliation. Macromolecular Materials and Engineering. 2012;297(5):444-454.

17. Martins CG, Larocca NM, Paul DR, Pessan LA. Nanocomposites formed from polypropylene/EVA blends. Polymer. 2009;50(7):17431754.

18. Fornes TD, Paul DR. Crystallization behavior of nylon 6 nanocomposites. Polymer. 2003;44(14):3945-3961.

19. Fornes TD, Yoon PJ, Keskkula H, Paul DR. Nylon 6 nanocomposites: the effect of matrix molecular weight. Polymer. 2001;42(25):9929-9940. 
20. Zhao J, Morgan AB, Harris JD. Rheological characterization of polystyrene-clay nanocomposites to compare the degree of exfoliation and dispersion. Polymer. 2005;46(20):8641-8860.

21. Menczel JD, Jaffe M. How did we find the rigid amorphous phase? Journal of Thermal Analysis and Calorimetry. 2007;89(2):357-362.

22. Ma Q, Cebe P. Phase structure of electrospun poly(trimethylene terephthalate) composite nanofibers containing carbon nanotubes. Journal of Thermal Analysis and Calorimetry. 2010;102(2):425-434.
23. Campoy LB, Gómez MA, Marco C. Structure and thermal properties of blends of nylon 6 and a liquid crystal copolymer. Polymer. 1998;39(25):6279-6288.

24. Wu TM, Chen EC, Liao CS. Polymorphic behavior of nylon 6/ saponite and nylon 6/montmorillonite nanocomposites. Polymer Engineering and Science. 2004;42(6):1141-1150.

25. ASTM International. ASTM D1003-13 - Standard Test Method for Haze and Luminous Transmittance of Transparent Plastics. West Conshohocken: ASTM International; 2013. 